\title{
Espaçamentos entre plantas e cobertura do solo com cama-de-frango na produção da bardana (Arctium lappa L.)
}

\author{
MUNARIN, E.E.O. ${ }^{1}$; HEREDIAZÁRATE, N.A. ${ }^{1 *}$; VIEIRA, M.C. ${ }^{1}$; ROSA, Y.B.C.J. ${ }^{1}$ RODRIGUES, E.T. ${ }^{2}$ \\ ${ }^{1}$ Faculdade de Ciências Agrárias/Universidade Federal da Grande Dourados- FCA/UFGD, Rodovia Dourados a \\ Itahum Km 12, Caixa Postal 533, CEP: 79.804-970, Dourados-BrasiF Universidade Estadual de Mato Grosso do \\ Sul-UEMS, Cidade Universitária de Dourados, Caixa Postal 351, CEP: 79.804-970, Dourados-Brasil \\ *nahz@terra.com.br
}

RESUMO: O objetivo do trabalho foi estudar o crescimento, o desenvolvimento e a produção da bardana em resposta a cinco espaçamentos entre plantas $(40,0 ; 47,5 ; 55,0 ; 62,5$ e 70,0 cm) e ao uso (CCF) ou não (SCF) de cobertura de solo com cama-de-frango semidecomposta. Os dez tratamentos foram arranjados como fatorial $5 \times 2$, no delineamento experimental blocos casualizados, com quatro repetições. As plantas foram propagadas inicialmente em berços de isopor e, posteriormente, em canteiros, arranjadas em fileiras duplas, espaçadas de 0,50 $\mathrm{m}$ entre fileiras simples e 1,0 m entre fileiras duplas. As avaliações de altura foram feitas a partir de 30 dias até 180 dias quando foi feita a colheita. As médias de altura $(172 \mathrm{~cm})$ e área foliar $\left(20.704 \mathrm{~cm}^{-2}\right)$ das plantas e as médias de comprimento $(23,6 \mathrm{~cm})$ e diâmetro das raízes $(16,2 \mathrm{~mm})$ não foram influenciadas significativamente pelos espaçamentos nem pela cobertura ou não do solo. Os maiores e menores valores para massas fresca $\left(25.676 \mathrm{~kg} \mathrm{ha}^{-1} \mathrm{e} 15.217 \mathrm{~kg} \mathrm{ha}^{-1}\right)$ e seca $(1.941,02$ $\mathrm{kg} \mathrm{ha}^{-1}$ e $\left.1.104,61 \mathrm{~kg} \mathrm{ha}^{-1}\right)$ de folhas, para o número de raízes $\left(490.750 \mathrm{ha}^{-1}\right.$ e $\left.272.120 \mathrm{ha}^{-1}\right)$ e para as massas fresca $\left(5.080,35 \mathrm{~kg} \mathrm{ha}^{-1} \mathrm{e} 3.546,25 \mathrm{~kg} \mathrm{ha}^{-1}\right)$ e seca $\left(1.448,91 \mathrm{~kg} \mathrm{ha}^{-1} \mathrm{e} 1.051,31 \mathrm{~kg} \mathrm{ha}^{-1}\right)$ de raízes foram encontrados com os espaçamentos de $40,0 \mathrm{~cm}$ e de $70,0 \mathrm{~cm}$ entre plantas, respectivamente, mostrando decréscimo linear na medida em que aumentaram os espaçamentos. Os teores de nitrogênio $(N)$ e de fósforo $(P)$, respectivamente, nas massas secas de folhas $(12,84$ $\mathrm{g} \mathrm{kg}^{-1}$ e $\left.0,33 \mathrm{~g} \mathrm{~kg}^{-1}\right)$ e de raízes $\left(4,11 \mathrm{~g} \mathrm{~kg}^{-1}\right.$ e $\left.0,13 \mathrm{~g} \mathrm{~kg}^{-1}\right)$ de bardana não foram influenciados significativamente pelos espaçamentos, mas sim pela cobertura ou não do solo com cama-defrango.

Palavras-chave: Planta medicinais, população de plantas, resíduo orgânico

\begin{abstract}
Spacing among plants and soil covering with poultry litter in burdock (Arctium lappa L.) production. The aim of this work was to study the growth, development and production of burdock in response to five spacing levels among plants $(40.0 ; 47.5 ; 55.0 ; 62.5$; and $70.0 \mathrm{~cm})$ and to the use (CCF) or not (SCF) of soil covering with semi-decomposed poultry litter. Experimental design was in randomized blocks, with four replicates, in a 5x2 factorial arrangement, with ten treatments. Plants were initially propagated in polystyrene plates; then, they were placed in flower beds and displayed in double rows, with $0.50 \mathrm{~m}$ spacing between simple rows and $1.0 \mathrm{~m}$ between double rows. Height was evaluated from 30 to 180 days, when harvest was performed. Mean height $(172 \mathrm{~cm})$, leaf area $\left(20,704 \mathrm{~cm}^{2}\right)$, root length $(23.6 \mathrm{~cm})$ and diameter $(16.2 \mathrm{~mm})$ were not significantly influenced by spacing or soil covering. The highest and lowest values of leaf fresh $\left(25,676 \mathrm{~kg} \mathrm{ha}^{-1}\right.$ and $\left.15,217 \mathrm{~kg} \mathrm{ha}^{-1}\right)$ and dry matter $\left(1,941.02 \mathrm{~kg} \mathrm{ha}^{-1}\right.$ and $\left.1,104.61 \mathrm{~kg} \mathrm{ha}^{-1}\right)$, root number $\left(490,750 \mathrm{ha}^{-1}\right.$ and $\left.272,120 \mathrm{ha}^{-1}\right)$ and fresh $\left(5,080.35 \mathrm{~kg} \mathrm{ha}^{-1}\right.$ and $\left.3,546.25 \mathrm{~kg} \mathrm{ha}^{-1}\right)$ and dry matter $\left(1,448.91 \mathrm{~kg} \mathrm{ha}^{-1}\right.$ and $\left.1,051.31 \mathrm{~kg} \mathrm{ha}^{-1}\right)$ were obtained at 40.0 and $70.0 \mathrm{~cm}$ spacing between plants, respectively, which shows a linear decrease with spacing increase. Nitrogen $(\mathrm{N})$ and phosphorous $(P)$ levels, in dry matter of leaves $\left(12.84 \mathrm{~g} \mathrm{~kg}^{-1}\right.$ and $\left.0.33 \mathrm{~g} \mathrm{~kg}^{-1}\right)$ and roots $(4.11 \mathrm{~g} \mathrm{~kg}$ ${ }^{1}$ and $0.13 \mathrm{~g} \mathrm{~kg}^{-1}$ ) of burdock, respectively, were not significantly influenced by spacing but by soil covering with poultry litter.
\end{abstract}

Key words: medicinal plants, plant population, organic residue

Recebido para publicação em 04/06/08

Aceito para publicação em 06/12/09

Rev. Bras. PI. Med., Botucatu, v.12, n.2, p.141-148, 2010. 


\section{INTRODUÇÃO}

A bardana (Arctium lappa L., Asteraceae) é originária da Europa e da Sibéria, chegou ao Brasil por meio dos imigrantes japoneses devido ao valor terapêutico e alimentar. É encontrada em países como Portugal, França, Espanha, Alemanha, Itália e na América do Sul (Morgan, 2003). Da bardana, utilizam-se raízes e folhas, frescas e secas, embora em alguns países, como a China, faça-se uso também das sementes como diurético, para tosse seca, resfriados, irritação da garganta e escarlatina. A infusão das folhas serve para limpar feridas e inflamações cutâneas. As raízes frescas são usadas em decocção, cataplasma e compressas (Martins et al., 2000).

As indicações terapêuticas da planta são amplas. São utilizadas para o controle de cólica nefrítica, gripes, constipação intestinal, dores de origem traumática, artrite, gota e insuficiência cardíaca. Ajuda no tratamento de queda de cabelos e enfermidades da pele (Morgan, 2003). Compostos extraídos da planta, apresentam ação inibitória sobre a replicação do vírus da imunodeficiência humana (HIV) (Vlietinck et al., 1998; Cho et al., 2004), que atua como anti-HIV (Kitamura et al., 1998), principalmente quando associada ao zinco, diminuindo a entrada do HIV nas células hospedeiras (Wang et al., 2004).

Atualmente, em vários países, a bardana é indicada em casos de enfermidades cancerosas, por isso vem se destacando popularmente como parte de chás (Martins et al., 2000; Gentil et al., 2006) e o efeito anticancerígeno foi confirmado por Ming et al. (2004), em hiperplasia da próstata. A toxicidade não é totalmente conhecida; porém, pode potencialmente causar sensibilização cutânea (Rodriguez et al., 1995). Sasaki et al. (2003) relataram um caso de anafilaxia como consequência da ingestão da planta. O consumo não é recomendado durante a gestação, devido à presença de atividade estimulante uterina (Cunha et al., 2003), que também é usada para restaurar hormônios (Correa et al., 1999).

No Brasil, a planta cresce espontaneamente nos campos e onde há solos ricos de matéria orgânica, sendo considerada muitas vezes planta invasora (Lorenzi \& Matos, 2002). O desenvolvimento é melhor em climas mais amenos, temperaturas que variam de 16 a $22^{\circ} \mathrm{C}$ e o espaçamento entre plantas deve ter no mínimo $30 \mathrm{~cm}$ e entre linhas, $50 \mathrm{~cm}$. O solo para o cultivo da bardana deve ser fértil, bem irrigado e drenado, de preferência arenoso, porque facilitará o aprofundamento e colheita das raízes (Correa et al., 1999).

Em Mato Grosso do Sul, devido ao grande incremento da avicultura de corte, há disponibilidade de volume e massa significativa de cama-de-frango semidecomposta. Na Grande Dourados, encontram- se mais de 430 aviários em produção e cada um produz em torno de $150 \mathrm{t}^{\mathrm{n} \mathrm{N}^{-1}}$ de cama-de-frango semidecomposta. Esse material pode ser aproveitado como fonte de resíduo orgânico para o cultivo de diversas espécies vegetais (Graciano et al., 2006).

O uso de resíduos orgânicos pode ser na forma de cobertura morta ou incorporada ao solo. Mesmo como cobertura poderá ter efeito benéfico, especialmente, em solos muito intemperizados de cerrados e com baixos teores de matéria orgânica, uma vez que estão sujeitos ao aquecimento e ressecamento da camada superficial. Isso porque, além de colaborar no incremento da produtividade e proporcionar a obtenção de plantas com características qualitativas melhores do que aquelas cultivadas exclusivamente com adubos minerais, podem atuar ainda como reguladora da temperatura do solo, retardando a fixação do fósforo e fornecendo produtos da decomposição orgânica, que favorecem o desenvolvimento da planta (Kiehl, 1985; Vieira \& Casali, 1997; Calegari, 1998).

Um dos primeiros pontos a considerar para buscar a otimização da produção é o espaçamento ideal, pois uma das formas de tentar aumentar a produtividade da cultura é cultivar um número maior de plantas por unidade de área. Entretanto, em geral, o aumento de produtividade por esse método tem limite, considerando que, com o aumento na densidade de população, cresce a competição entre plantas, sendo o desenvolvimento individual prejudicado, podendo, inclusive, ocorrer queda no rendimento e ou na qualidade (Minami et al., 1998). Larcher (2000) ressalta que a densidade de plantio favorece a produtividade de diversas espécies vegetais, desde que não afete a produção e a partição de fotoassimilados.

O objetivo deste trabalho foi estudar o crescimento, o desenvolvimento e a produção da bardana em resposta a cinco espaçamentos entre plantas e ao uso ou não de cobertura do solo com cama-de-frango semidecomposta.

\section{MATERIAL E MÉTODO}

O experimento foi desenvolvido no Horto de Plantas Medicinais (HPM), da Fazenda Experimental de Ciências Agrárias, da Universidade Federal da Grande Dourados - UFGD - MS no período de 14 de fevereiro a 20 de outubro de 2006. Dourados situa-se a altitude de $430 \mathrm{~m}$, latitude de $22^{\circ} 14^{\prime} 16^{\prime \prime S}$, longitude 5448'2" W. O clima, segundo a classificação de Köppen (1948), é do tipo Mesotérmico Úmido. A precipitação média anual é de $1500 \mathrm{~mm}$ e a temperatura média é de $22^{\circ} \mathrm{C}$. A topografia do local é plana e o solo classificado como Latossolo Vermelho distroférrico, originalmente sob vegetação de Cerrado.

Os resultados das análises químicas do solo

Rev. Bras. Pl. Med., Botucatu, v.12, n.2, p.141-148, 2010. 
antes do transplante foram $\mathrm{pH}$ em $\mathrm{CaCl}_{2}(1: 2,5)=4,90$; pH em água $(1: 2,5)=5,50 ; \mathrm{Al}^{+3}\left(\mathrm{mmol}_{\mathrm{c}} \mathrm{dm}^{-3}\right)=1,12 ; \mathrm{P}$ $\left(\mathrm{mg} \mathrm{dm}^{-3}\right)=53,00 ; \mathrm{K}\left(\mathrm{mmol}_{\mathrm{c}} \mathrm{dm}^{-3}\right)=10,30 ; \mathrm{Mg}\left(\mathrm{mmol}_{\mathrm{c}}\right.$ $\left.\mathrm{dm}^{-3}\right)=16,60 ; \mathrm{Ca}\left(\mathrm{mmol}^{\mathrm{d}} \mathrm{dm}^{-3}\right)=48,00$; matéria orgânica $\left(\mathrm{g} \mathrm{kg}^{-1}\right)=30,00$; acidez potencial $(\mathrm{H}+\mathrm{Al})\left(\mathrm{mmol}_{\mathrm{c}} \mathrm{dm}^{-3}\right)=68,00$; Soma de bases (SB) $\left(\mathrm{mmol}_{\mathrm{c}} \mathrm{dm}^{-3}\right)=77,10 ;(\mathrm{CTC})\left(\mathrm{mmol}_{\mathrm{c}} \mathrm{dm}^{-3}\right)=145,50$; Saturação de bases (V) \%=51,00. A cama-de-frango semidecomposta utilizada teve como base a casca de arroz e teve a composição de $\mathrm{C}_{\text {orgânico }}(\%)=29,12$; $\mathrm{P}_{\text {total }}(\%)=1,15 ; \mathrm{N}_{\text {total }}(\%)=1,75 ; \mathrm{K}_{\text {total }}(\%)=0,63 ; \mathrm{Ca}_{\text {total }}(\%)$ $=3,58 ; \mathrm{Mg}_{\text {total }}(\%)=0,69$ e relação $\mathrm{C} / \mathrm{N}=16,64$.

Foi estudada a bardana com cinco espaçamentos entre plantas $(40,0 ; 47,5 ; 55,0 ; 62,5$; e 70,0 cm), sem cobertura (SCF) e com cobertura (CCF). Para cobertura foi utilizado $10 \mathrm{t} \mathrm{ha}^{-1}$ de cama de frango semidecomposta. Os dez tratamentos foram arranjados como fatorial $5 \times 2$, no delineamento experimental de blocos casualizados, com quatro repetições. Cada parcela teve área total de $5,25 \mathrm{~m}^{2}$ (1,5 m de largura e 3,5 m de comprimento) e área útil de $3,5 \mathrm{~m}^{2}$ (1,0 $\mathrm{m}$ de largura e 3,5 $\mathrm{m}$ de comprimento), com as plantas arranjadas em fileira dupla, espaçadas de $0,50 \mathrm{~m}$ entre fileiras simples e 1,0 m entre fileiras duplas.

A propagação da bardana ocorreu por semeadura indireta, utilizando-se sementes colhidas de plantas cultivadas no HPM da UFGD. As sementes foram colocadas em berços de isopor, com células preenchidas com substrato comercial Plantmax $\mathrm{HA}^{\circledR}$, sobre bancadas de madeira no interior de viveiro telado, com $50 \%$ de sombreamento, provido de filme plástico transparente na cobertura e de sistema de irrigação por micro aspersão.

Após 30 dias da semeadura, quando as mudas tinham cerca de $5 \mathrm{~cm}$ de altura, foram repicadas para sacos plásticos de $8,0 \mathrm{~cm} \times 15,0 \mathrm{~cm}$, preenchidos com substrato composto por terra, camade-frango semidecomposta e areia grossa, na proporção 3:1:1, em volume.

O transplante das mudas para o local definitivo ocorreu aos 60 dias após a semeadura, quando as plântulas atingiram altura em torno de 15 $\mathrm{cm}$, nos espaçamentos previamente determinados.

O solo da área para o transplante das mudas foi preparado três dias antes, com aração e gradagem, seguido de levantamento dos canteiros com rotoencanteirador. Após o transplante, foi realizada a cobertura do solo com a cama-de-frango semidecomposta, nas parcelas correspondentes.

Os tratos culturais, entre o transplante e a colheita, incluíram irrigações diárias, utilizando o sistema de aspersão, com o intuito de manter o solo com 70 a $75 \%$ da capacidade de campo e o controle de plantas infestantes, fazendo-se capinas com enxada, nas entre linhas, e com arranquio manual nas linhas.
No período de 30 até os 180 dias (época da colheita) após o transplante foram avaliadas quinzenalmente as alturas de todas as plantas das parcelas, usando-se régua graduada em centímetros, colocada desde o nível do solo até a inflexão da folha mais alta.

As plantas foram colhidas com auxílio de enxada e pá e depois separadas em folhas e raízes (que foram lavadas) com instrumento cortante.

As raízes obtidas por planta foram contadas, com posterior transformação em número ha-1.

As lâminas foliares foram usadas para a determinação da área foliar $\left(\mathrm{cm}^{2}\right)$, utilizando-se o integrador eletrônico LI COR 3000.

Posteriormente, foram escolhidas seis raízes, sendo duas maiores, duas médias e duas menores, para avaliação do diâmetro $(\mathrm{mm})$ na altura do coleto e o comprimento $(\mathrm{cm})$, com paquímetro e régua graduada em centímetros, respectivamente.

As partes das plantas foram acondicionadas separadamente em sacos de papel e pesadas em balança digital, com resolução $0,1 \mathrm{~g}$, para determinação da massa fresca, em $\mathrm{g}$, com posterior transformação em kg ha-1. Posteriormente, o material foi colocado em estufa com circulação forçada de ar, a $60^{\circ} \pm 5^{\circ} \mathrm{C}$, até massa constante, com posterior pesagem em g e transformação em $\mathrm{kg} \mathrm{ha}^{-1}$.

Para a altura de plantas, foi utilizado o delineamento em blocos ao acaso com as alturas como parcelas subdivididas no tempo, submetidos à análise de variância e de regressão em função dos dias após o transplante, para cada tratamento.

Os dados de produção foram submetidos à análise de variância e as médias relacionadas com o uso ou não da cama-de-frango para cobertura do solo foram comparadas pelo teste $F$, até $5 \%$ de probabilidade. Para os efeitos de espaçamentos entre plantas foram ajustadas equações de regressão e o recurso gráfico do Excel (Ribeiro Júnior, 2001).

Nas massas secas de folhas e raízes da bardana, após a moagem, foram analisados os teores de $\mathrm{N}$ e $\mathrm{P}$, em extratos obtidos através da digestão sulfúrica para o $\mathrm{N}$ e nítrico-perclórico para o $\mathrm{P}$, seguidas por destilação e titulação. Após a digestão, foram realizadas a determinação do $\mathrm{N}$ pelo método semi-micro Kjeldahl e a do P, pelo colorímetro por vanadato molibdato (Malavolta et al., 2006). Os valores obtidos foram apresentados em $\mathrm{g} \mathrm{kg}^{-1}$.

\section{RESULTADO E DISCUSSÃO}

A altura das plantas de bardana não foi influenciada estatisticamente pelos espaçamentos entre plantas nem pela cobertura do solo com cama de frango semidecomposta (CCF). Segundo Taiz \& Zeiger (2006), os sistemas vegetais apresentam mecanismos de auto-regulação, baseando-se na 
capacidade de adaptação do organismo individual e das populações ou no equilíbrio das relações de interferência, como competição por nutrientes, água e luz, que influencia na produção e na partição de fotoassimilados. As plantas cultivadas em solo CCF apresentaram altura média máxima de $175 \mathrm{~cm}$, enquanto as cultivadas em solo sem cama-de-frango - SCF, de $170 \mathrm{~cm}$.

A produção de massa fresca das folhas da bardana não foi influenciada pela interação entre os fatores, mas sim pelos espaçamentos, com resposta linear decrescente na medida em que aumentaram os espaçamentos entre plantas (Figura 1). A maior produtividade foi de $25.676 \mathrm{~kg} \mathrm{ha}^{-1}$, com espaçamento de $40,0 \mathrm{~cm}$ entre plantas e a menor foi de $15.217 \mathrm{~kg} \mathrm{ha}^{-1}$, com 70,0 cm. Esses resultados permitem levantar a hipótese de que nas plantas, sob populações adensadas, os processos metabólicos podem ter sido eficazes, aproveitando melhor os recursos do ambiente. Por outro lado, não houve diferenças significativas entre a produtividade de massa fresca de folhas das plantas de bardana em solo CCF $(21.180,87 \mathrm{~kg}$ $\left.\mathrm{ha}^{-1}\right)$ e em solo SCF $\left(20.412,03 \mathrm{~kg} \mathrm{ha}^{-1}\right)$, embora tenha havido tendência favorável à planta com o uso da cama-de-frango.

A área da lâmina foliar da bardana não foi influenciada estatisticamente pelos espaçamentos entre plantas nem pelo uso ou não da cobertura do solo com cama-de-frango semidecomposta. Como a bardana é planta de sombra (Lorenzi \& Matos, 2002), provavelmente houve equilíbrio da fonte fotossintética e dos drenos metabólicos para todos os tratamentos estudados. As plantas cultivadas em solo CCF apresentaram área foliar de $21.054,80 \mathrm{~cm}^{2}$ planta-1 $^{-1}$ enquanto em solo SCF foi de $19.971,80 \mathrm{~cm}^{2}$ planta-1. A massa seca de folhas das plantas da bardana teve efeito significativo dos espaçamentos entre plantas, decrescendo linearmente à medida que aumentaram os espaçamentos entre plantas (Figura 2), à semelhança do que aconteceu com a massa fresca (Figura 1). A maior produtividade de massa seca de folhas foi de $1.941,02 \mathrm{~kg} \mathrm{ha}^{-1} \mathrm{com}$ espaçamento de $40,0 \mathrm{~cm}$ entre plantas e superou em $836,41 \mathrm{~kg}$ ha $^{-1}$ à produção quando espaçamento de $70,0 \mathrm{~cm}$, que foi a menor. Os resultados mostram relação com a citação de Larcher (2000) sobre a maximização da produção depender da população empregada em função da capacidade suporte do meio, sistema de produção adotado e da adequada distribuição espacial das plantas na área, em conformidade com as características genotípicas.

A produtividade de massa seca de folhas nas plantas cultivadas em solo CCF foi de $1.605,07 \mathrm{~kg}$ ha $^{-1}$ e em solo SCF foi de $1.434,31 \mathrm{~kg} \mathrm{ha}^{-1}$, sem se diferenciarem estatisticamente. Isso permite supor, que houve respostas modificativas internas que adaptaram as plantas às condições ambientais prevalecentes durante o ciclo da cultura (Larcher, 2000).

O número de raízes das plantas da bardana foi influenciado significativamente pelos espaçamentos entre plantas, com respostas lineares e decrescentes à medida que aumentaram os espaçamentos entre plantas (Figura 3). O maior número de raízes obtido foi de 490.750 ha $^{-1}$ com espaçamento de $40,0 \mathrm{~cm}$ entre plantas e o menor foi de $272.120 \mathrm{ha}^{-1}$, com 70,0 $\mathrm{cm}$. Gassi (2009), quando estudou a bardana com doses de fósforo e cama-de-frango semidecomposta incorporadas, nos espaçamentos de $50,0 \mathrm{~cm}$ entre plantas e $54,0 \mathrm{~cm}$ entre linhas constatou que o maior número de raízes foi de $484.960 \mathrm{ha}^{-1}$, quando utilizou $19.000 \mathrm{~kg} \mathrm{ha}^{-1}$ de cama-de-frango e $60,2 \mathrm{~kg} \mathrm{ha}^{-1} \mathrm{de}$ fósforo, isoladamente e o menor número foi de 230.050

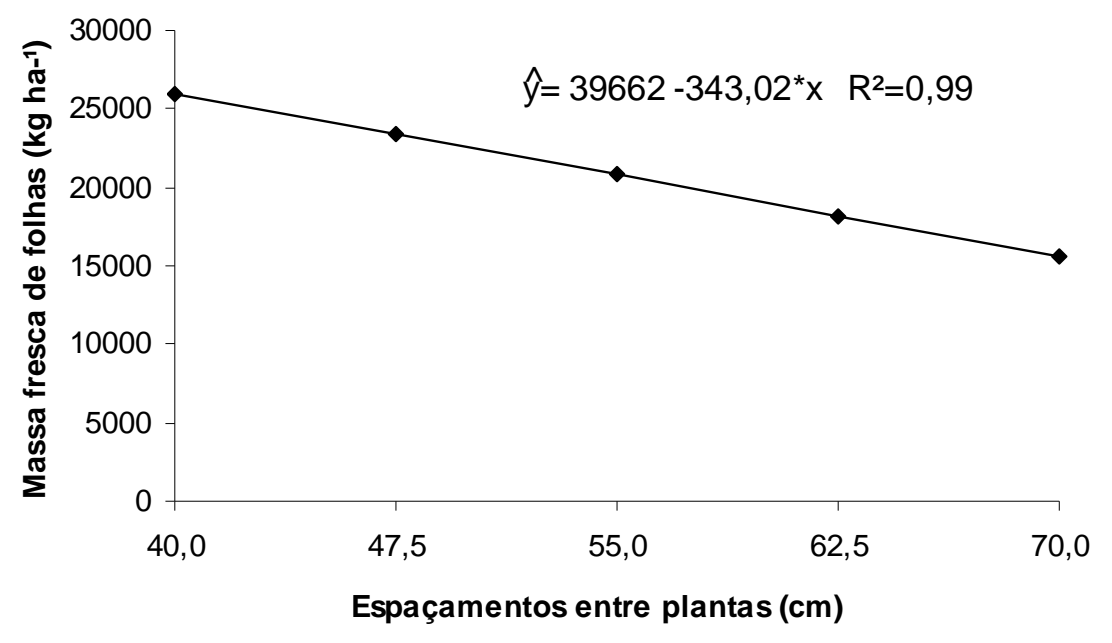

FIGURA 1. Massas frescas de folhas de plantas de bardana cultivadas sob cinco espaçamentos entre plantas. UFGD, Dourados-MS, 2006. CV = 30,0\%. 


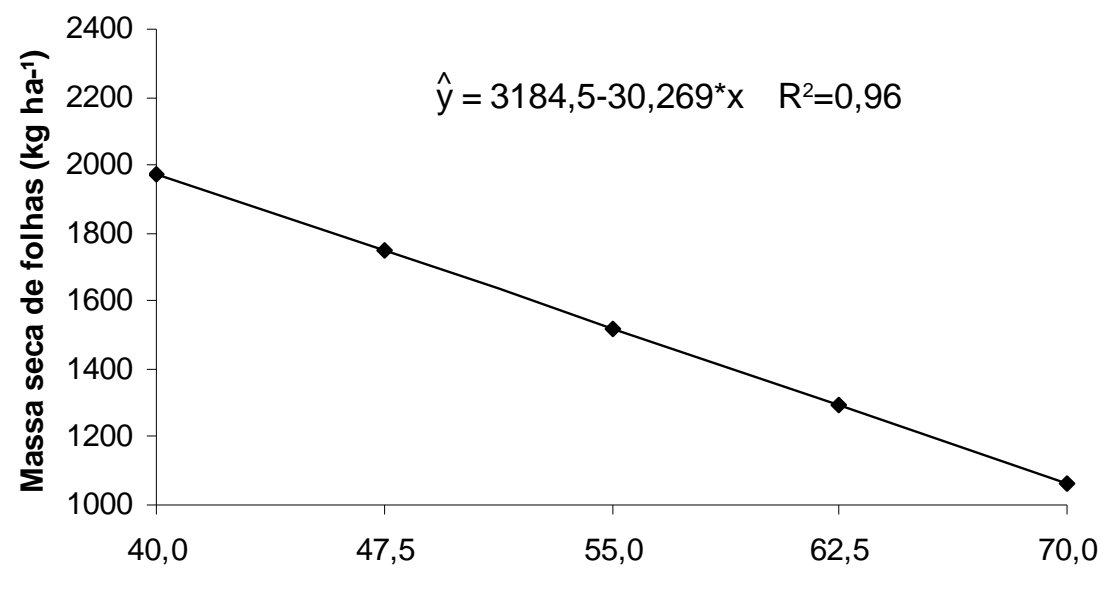

Espaçamentos entre plantas (cm)

FIGURA 2. Massa seca de folhas de plantas de bardana cultivadas sob cinco espaçamentos. UFGD, DouradosMS, 2006. $C V=32,95 \%$.

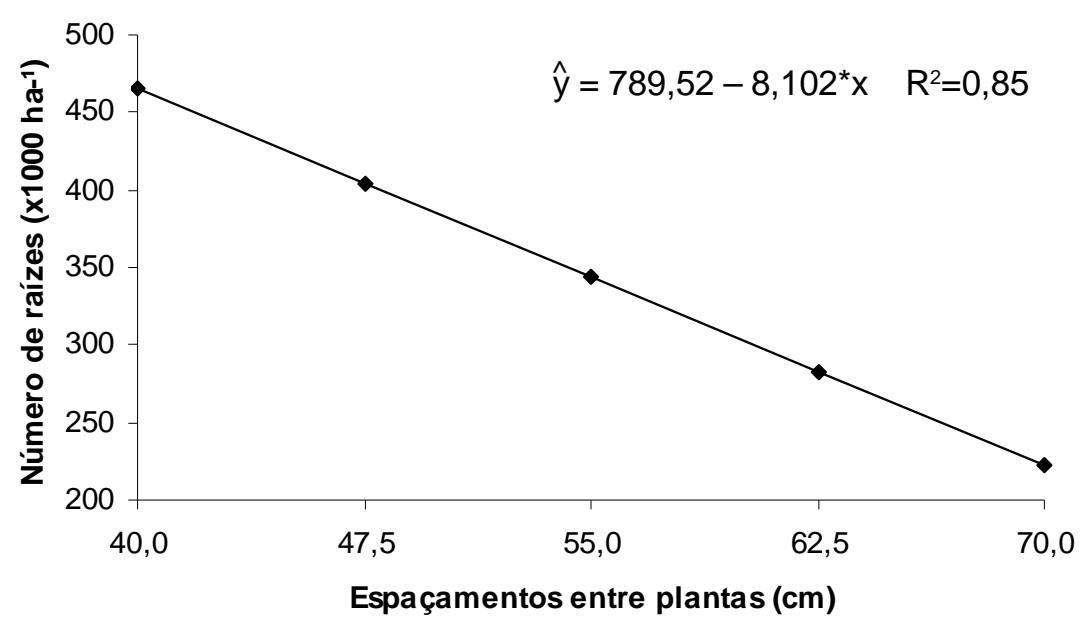

FIGURA 3. Número de raízes $\left(1000 \mathrm{ha}^{-1}\right)$ de plantas de bardana cultivadas sob cinco espaçamentos entre plantas, UFGD, Dourados-MS. 2006. CV = 34,90\%.

ha $^{-1}$. As plantas cultivadas em solo CCF produziram 348.550 raízes ha-1 e não se diferenciaram estatisticamente daquelas cultivadas em solo SCF, que produziram 329.211 raízes ha-1.

O comprimento e o diâmetro das raízes das plantas da bardana não foram influenciados significativamente pelos tratamentos. Tais resultados indicam que, nas condições experimentais, essas características das raízes comportaram-se como genotípicas; isso porque o sistema radicular da planta desenvolve-se seguindo padrão morfológico particular para cada espécie e estende-se conforme a estrutura e profundidade do solo (Larcher, 2000). Gassi et al. (2009), quando estudou a bardana com doses de fósforo e cama-de-frango semidecomposta incorporadas, nos espaçamentos de $50,0 \mathrm{~cm}$ entre plantas e 54,0 cm entre linhas, constataram que 0 comprimento e o diâmetro das raízes não apresentaram diferenças estatísticas em função dos tratamentos utilizados, com os valores médios de 18,6 $\mathrm{cm}$ e 9,1 mm, respectivamente, que foram inferiores aos resultados deste trabalho, onde obtiveram, em média, $23,6 \mathrm{~cm}$ de comprimento e $16,2 \mathrm{~mm}$ de diâmetro.

A produção de massa fresca das raízes da bardana foi influenciada significativamente pelos espaçamentos entre plantas, apresentando decréscimo linear à medida que aumentaram os espaçamentos (Figura 4), tal como ocorreu com as massas fresca (Figura 1) e seca (Figura 2) das folhas e número de raízes (Figura 3 ).

A maior produtividade de raízes foi de $5.080,35 \mathrm{~kg} \mathrm{ha}^{-1}$, com espaçamento de $40,0 \mathrm{~cm}$ entre plantas e a menor foi de $3.546,25 \mathrm{~kg} \mathrm{ha}^{-1}$, quando com $70,0 \mathrm{~cm}$. O fato de o menor espaçamento ter induzido maior produtividade indica que, provavelmente, não se chegou à pressão populacional que diminuísse a capacidade produtiva total das plantas, devido à 
competição por fatores de crescimento, tais como radiação solar fotossinteticamente ativa, água e nutrientes, o que acarretaria em decréscimo da produtividade.

A produtividade de massa fresca de raízes não foi influenciada significativamente em solo CCF $\left(4.259,1 \mathrm{~kg} \mathrm{ha}^{-1}\right)$, em relação ao SCF $(4.072,3 \mathrm{~kg}$ $\left.\mathrm{ha}^{-1}\right)$, embora a diferença tenha sido de $186,75 \mathrm{~kg} \mathrm{ha}^{-1}$.

A produção de massa seca das raízes da bardana (Figura 5) foi influenciada pelos espaçamentos, seguindo a mesma tendência da massa fresca de raízes (Figura 4), onde houve

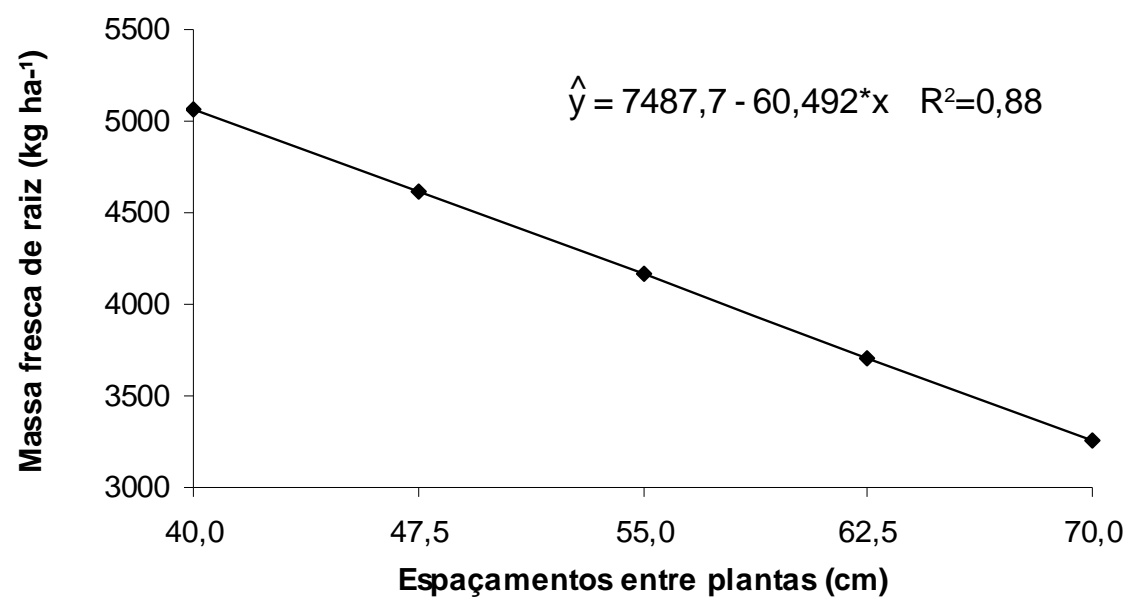

FIGURA 4. Massas frescas de raízes de plantas de bardana cultivadas sob cinco espaçamentos entre plantas. UFGD, Dourados-MS, 2006. CV $=25,14 \%$.

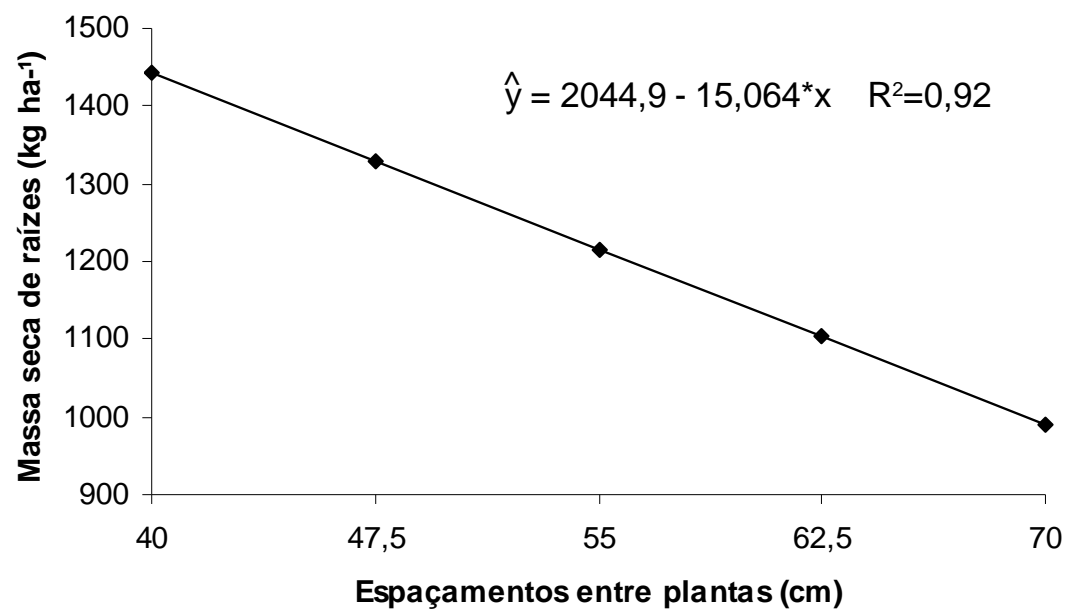

FIGURA 5. Massas secas de raízes de plantas de bardana cultivadas sob cinco espaçamentos entre plantas. UFGD, Dourados-MS, 2006. CV $=26,49 \%$.

diminuição linear à medida em que aumentavam os espaçamentos entre plantas.

A maior produtividade de massas secas de raízes foi de $1.448,91 \mathrm{~kg} \mathrm{ha}^{-1}$ com espaçamento de $40,0 \mathrm{~cm}$ entre plantas e a menor, de $1.051,31 \mathrm{~kg} \mathrm{ha}^{-1}$, com $70,0 \mathrm{~cm}$. Provavelmente, o maior adensamento tenha proporcionado maior sombreamento e mantido a umidade do solo, favorecendo ambiente adequado.

A variação da produtividade das plantas cultivadas em solo CCF $\left(1.240,03 \mathrm{~kg} \mathrm{ha}^{-1}\right)$ e em solo
SCF $\left(1.192,73 \mathrm{~kg} \mathrm{ha}^{-1}\right)$ não foi estatisticamente diferente.

Os teores de $\mathrm{N}$ (Figura 6A) e de $\mathrm{P}$ (Figura 6B) nas massas secas de folhas e de raízes da bardana foram influenciados significativamente pela cobertura do solo com cama-de-frango semidecomposta. Isso ocorreu, provavelmente, devido ao fato de que o resíduo orgânico, mesmo sob a forma de cobertura, pode ter agido indiretamente na disponibilidade e retenção dos nutrientes. 

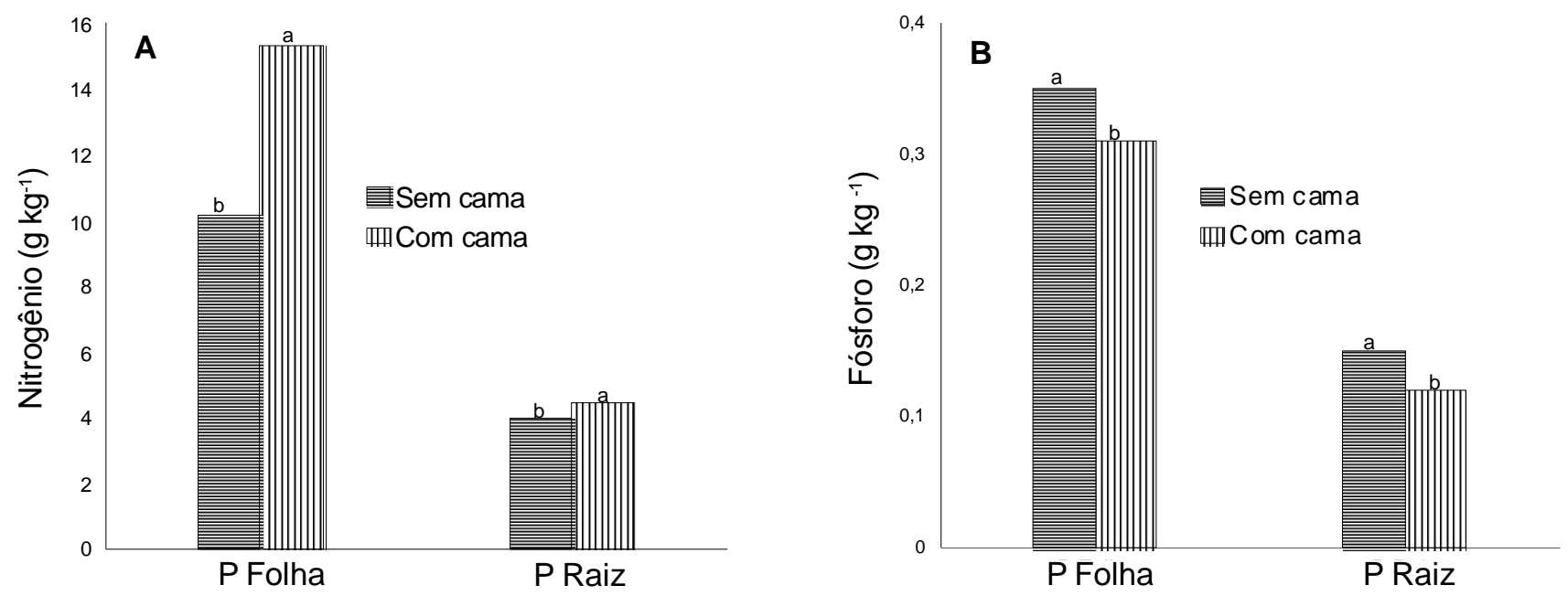

FIGURA 6. Teores de nitrogênio (A) e fósforo (B) nas massas secas de folhas e de raízes de plantas de bardana, com - CCF e sem - SCF cama-de-frango na cobertura do solo. UFGD, Dourados-MS, 2006. CV =30,78\% e 7,11\%, respectivamente.

Os teores de $\mathrm{N}$ encontrados na massa seca das folhas foram maiores que os encontrados nas raízes, provavelmente, porque nas folhas se acumulam os principais elementos nutritivos, N, P, K e outros, para uso posterior no resto da planta (Larcher, 2000) e porque o grau de mobilidade depende em grande parte da mobilidade dos íons no floema (Epstein \& Bloon, 2006).

Os teores de $\mathrm{N}$ encontrados na massa seca das folhas e de raízes foram maiores nas plantas cultivadas em solo CCF em relação às cultivadas em solo SCF. Já, para o $\mathrm{P}$ o maior teor foi nas plantas cultivadas em solo SCF. Segundo Malavolta (2006), os teores de nutrientes nas plantas são específicos para a espécie, idade e tecido, como também, dependem do ambiente. A taxa de absorção de um nutriente pela planta depende dos cátions dissolvidos na solução de solo em equilíbrio dinâmico com os cátions do complexo de troca. Desse modo, vários são os fatores que controlam o teor de elementos nos vegetais, principalmente o genético.

Embora os teores médios de $\mathrm{N}$ obtidos nas massas secas das folhas $\left(12,84 \mathrm{~g} \mathrm{~kg}^{-1}\right)$ e das raízes da bardana $\left(4,11 \mathrm{~g} \mathrm{~kg}^{-1}\right)$ tenham sido inferiores aos estabelecidos por Malavolta et al. (1997) (20 a $50 \mathrm{~g}$ $\mathrm{kg}^{-1}$ na massa seca, exigidos para o ótimo crescimento das grandes culturas) e como nenhum sintoma de deficiência visual desses nutrientes foram observados, pode-se supor que os valores obtidos foram suficientes para o desenvolvimento da bardana, nas condições experimentais.

Nas condições em que foi conduzido o experimento, conclui-se que a cobertura do solo com cama-de-frango de corte semidecomposta não influenciou a produtividade da bardana e deve-se recomendar para o cultivo o espaçamento de $40 \mathrm{~cm}$ entre plantas, tanto com o objetivo de produção de folhas como de raízes.

\section{REFERÊNCIA}

CALEGARI, A. Espécies para cobertura do solo. In: INSTITUTO AGRONÔMICO DO PARANÁ. Plantio direto: pequena propriedade sustentável. Londrina: IAPAR, 1998. p.65-94.

$\mathrm{CHO}, \mathrm{M} . \mathrm{K}$. et al. Arctigenin, a phenylpropanoid dibenzylbutyrolactone lignan, inhibits MAP kinases and AP-1 activation via potent MKK inhibition: the role in TNF inhibition. International Immunopharmacology, v.4, p.1419-29, 2004.

CORREA, A.D.; BATISTA, R.S.; QUINTAS, L.E. Plantas medicinais: do cultivo à terapêutica. 2.ed. Rio de Janeiro: Vozes, 1999. 246p.

CUNHA, A.P.; SILVA, A.P.; ROQUE, O.R. Plantas e produtos vegetais em fitoterapia. Lisboa: Fundação Calouste Gublenkian, 2003. 701p.

EPSTEIN, E.; BLOOM, A.J. Nutrição mineral de plantas: princípios e perspectivas. 2.ed. Trad. NUNES, M.E.T. Londrina: Planta. 2006. 403p.

GASSI, R.P. et al. Doses de fósforo e de cama-de-frango na produção de bardana. Ciência e Agrotecnologia, v.33, n.3, p.692-7, 2009.

GENTIL, M. et al. In vitro evaluation of the antibacterial activity of Arctium lappa L. as a phytotherapeutic agent used in intracanal dressigs. Phytotherapy Research, v.20, n.3, p.183-6, 2006.

GRACIANO, J.D. et al. Efeito da cobertura do solo com cama-de-frango semidecomposta sobre dois clones de mandioquinha-salsa. Acta Scientiarum: Agronomy, v.28, n.3, p.367-73, 2006.

KIEHL, E.J. Fertilizantes orgânicos. Piracicaba: Agronômica Ceres, 1985. 492p.

KITAMURA, K. et al. Baicalin, an inhibitor of HIV-1 
production in vitro. Antiviral Research, v.37, n.2, p.13140, 1998.

KÖPPEN, W. Climatologia: con un estudio de los climas de la tierra. México: Fondo de Cultura Económica, 1948. 478p.

LARCHER, W. Ecofisiologia vegetal. São Carlos: RimaArtes e Textos, 2000. 531p.

MALAVOLTA, E. Manual de nutrição mineral de plantas. São Paulo: Agronômica Ceres, 2006. 638p.

LORENZI, H.; MATOS, F.J.A. Plantas medicinais no Brasil: nativas e exóticas cultivadas. Nova Odessa: Plantarum, 2002. 544p.

MALAVOLTA, E.; VITTI, C.G.; OLIVEIRA, S.A. Avaliação do estado nutricional das plantas: princípios e aplicações. Piracicaba: POTAFÓS, 1997. 319p.

MARTINS, E.R. et al. Plantas medicinais. 2.ed. Viçosa: UFV, Imprensa Universitária, 2000. 220p.

MINAMI, K. et al. Efeito do espaçamento sobre a produção em rabanete. Bragantia, v.57, n.1, p.169-76, 1998.

MING, D.S. et al. Isolation and characterization of compounds with anti-prostate cancer activity fron Arctium lappa L. using bioactivity-guided fractionation.
Pharmaceutical Biology, v.42, n.1, p.44-8, 2004. MORGAN, R. Enciclopédia das ervas e plantas medicinais. 9.ed. São Paulo: Hemus, 2003. 555p. RIBEIRO JUNIOR, J.I. Análises estatísticas no SAEG. Viçosa: UFV, 2001. 301p.

RODRIGUEZ, P.; BLANCO, J.; JUSTE, S. Allergic contact dermatitis due to burdock. Contact Dermatitis, v.33, p.134-5, 1995.

SASAKI, Y. et al. Anaphylaxis due to burdock. International Journal of Dermatology, v.42, n.2, p.472-3, 2003.

TAIZ, L.; ZEIGER, E. Fisiologia Vegetal. Porto Alegre: Artmed, 2006. p.328-37.

VIEIRA, M.C.; CASALI, V.W.D. Adaptação da cultura da mandioquinha-salsa à adubação orgânica. Informe Agropecuário, v.19, p.40-2, 1997.

VLIETINCK, A.J. et al. Plant-derived leading compounds for chemotherapy of human immunodeficiency virus (HIV) infection. Planta Medicinale, v.64, n.2, p.97-109, 1998.

WANG, Q. et al. Zinc coupling potentiates anti-HIV-1 activity of baicalin. Biochemical and Biophysical Research Communications, v.324, n.2, p.605-10, 2004. 